\title{
Current Opinion
}

\section{Timing of Neuraxial Pain Interventions Following Blood Patch for Post Dural Puncture Headache}

Naum Shaparin, MD¹, Karina Gritsenko, MD¹, David Shapiro, MD², Boleslav Kosharskyy, MD", Alan David Kaye, MD, PhD ${ }^{3}$, and Howard S. Smith, MD ${ }^{4}$

From: ${ }^{1}$ Montefiore Medical Center/ Albert Einstein College of Medicine, Bronx, New York; ${ }^{2}$ The Mount Sinai Medical Center/Icahn School of Medicine at Mount Sinai, New York,

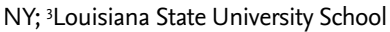
of Medicine, New Orleans; ${ }^{4}$ Albany Medical College, Albany, New York

Additional author affiliation and conflict information on p. 123-124

Address Correspondence: Karina Gritsenko, MD Assistant Professor, Department of Anesthesiology Assistant Professor, Department of Family and Social Medicine Montefiore Medical Center/Albert

Einstein College of Medicine 3300 Bainbridge Ave

Map building, basement level Bronx, New York 10467 E-mail:

karina.gritsenko@gmail.com

Disclaimer: There was no external funding in the preparation of this manuscript.

Manuscript received: 10-09-2013 Revised manuscript received: 12-20-2013 Accepted for publication: 12-24-2013

Free full manuscript: www.painphysicianjournal.com
Post dural puncture headache (PDPH) is a common complication of interventional neuraxial procedures. Larger needle gauge, younger patients, low body mass index, women (especially pregnant women), and "traumatic" needle types are all associated with a higher incidence of PDPH. Currently, an epidural blood patch is the gold-standard treatment for this complication. However, despite the high PDPH cure rate through the use of this therapy, little is known about the physiology behind the success of the epidural blood patch, specifically, the time course of patch formation within the epidural space or how long it takes for the blood patch volume to be resorbed by the body. Of the many unanswered and debated topics related to PDPH and epidural blood patches, one additional specific question that may alter clinical management is when it is safe for patients who have experienced a disruption of the thecal space and have undergone this procedure to have a subsequent epidural or spinal procedure, such as a neuraxial anesthetic (i.e. a spinal anesthetic for an elective outpatient procedure) or an interventional pain procedure for chronic pain management. This question becomes more unclear if the new procedure includes a steroid medication. As an example, an older patient presents with a history of lumbar disc disease and during lumbar epidural steroid injection, an inadvertent wet tap occurs leading to PDPH. Following management with fluids, caffeine, medications, and a successful epidural blood patch, it remains unclear as to when would be the best time frame to consider a second lumbar epidural steroid injection. We identified the 3 main risk factors of subsequent interventional neuraxial procedures as (1) disruption of the epidural blood patch and ongoing reparative processes, (2) epidural procedure failure, and (3) infection. We looked at the literature, and summarized the existing literature in order to enable health care professionals to understand the time course of dural repair as well as the risks of subsequent neuraxial procedures after epidural blood patches. This review poses the question using an evidence based review to discuss the appropriate time course to proceed.

Key words: Post dural puncture headache, epidural steroid injection, wet tap, timing of therapy

Pain Physician 2014; 17:119-125
D ost dural puncture headache (PDPH) is common in both anesthesiology and interventional pain medicine practices. PDPH typically is a self-limited condition, with the majority of cases resolving within a week via administration of conservative treatment (e.g. hydration, rest, caffeine, and analgesics). This resolution most commonly occurs with or without the most effective, yet more invasive treatment: an epidural blood patch. Although most PDPH are selflimiting and last for several days, in severe cases, PDPHs can persist for several weeks to months and can be extremely debilitating with associated morbidity $(1,2)$. Despite the success of the epidural blood patch, many questions remain which have gone either unanswered or remain controversial. This review attempts to answer some of these questions to assist the clinician who has a patient that received a $\mathrm{PDPH}$.

The incidence of unintentional dural puncture after neuraxial procedures is about 1\% (3-5). According to the literature, of the patients who experience 
this complication, the onset of a post dural puncture headache can be quite variable, ranging from $<1 \%$ to $86 \%(6-8)$, with an overall incidence approaching $8 \%$ (9). Several factors are believed to affect the incidence of PDPH, including needle gauge, patient specific factors, and needle design.

Needle gauge is believed to be the most important factor affecting the incidence of PDPH (10); several studies have shown a direct relationship between needle gauge and the incidence of PDPH (11-14). Attempts to decrease the incidence of PDPH by using smaller gauge needles (such as 29 - 32 gauge needles) have been met with limited success; while these smaller gauge needles decrease the incidence of PDPHs, they are associated with a higher incidence of failed anesthesia (14).

Patient demographics are also important in $\mathrm{PDPH}$ risk stratification. Patients at highest risk of PDPH include younger patients (15-18), those with a low body mass index $(15,19)$, and women (16-18). Some experts attribute the difference in PDPH rates to differences in pain perception or cerebral vessel reactivity related to differing hormone levels, dural elasticity, or the fact that older individuals have lower cerebrospinal fluid (CSF) pressures. The higher rate of PDPH in pregnant women may be due to a decline in CSF density and an increase in intra-abdominal pressure-both of which may induce CSF leakage (20).

Additionally, certain needle designs have been shown to place patients at higher risk of developing PDPH. There is an overwhelming body of evidence from studies in the literature that pencil point or "atraumatic" needle types (like Whitacre and Sprotte) reduce the incidence of PDPH, as compared to cutting or "traumatic" needle types (like Quinke) (21-23). This may be because rather than cutting the dura, these needles separate the elastic dural fibers (24). As a result of this "separation," dural fibers are able to return to their original position once the spinal needle is removed, thereby minimizing dural damage (25). However, at the electron microscopy level, use of pencil needles actually create more trauma to the dura, producing more irregular tears in the dura which may trigger a larger inflammatory reaction that prevents CSF leakage (26). Regardless of mechanism, atraumatic needles are associated with a lower incidence of PDPH.

Conservative options for treating PDPH include rest, fluids, caffeine, and medications, including cosyntropin and sumatriptan, among others. In recent years, there has been a trend away from these management strategies as they have been shown to be relatively ineffective when compared to an epidural blood patch. For over 50 years, epidural blood patch continues to be a safe, reliable, and effective method for treating patients who suffer from moderate to severe PDPH. In fact, epidural blood patch has increasingly been seen as the gold standard for the treatment of PDPH (27). Most literature regarding the incidence of PDPH is from obstetrical and surgical patient populations with minimal commentary relating to interventional pain practice.

Since many patients receiving conservative measures such as rest, fluids, caffeine, and various medications are not studied, it is difficult to precisely measure this patient population related to lack of reporting and symptom improvement. Without doubt, those that fail conservative measures typically proceed to an epidural blood patch for relief of PDPH.

According to several reports in the literature, the success rate of the epidural blood patch ranges from $61 \%$ to $89 \%$, and can approach $100 \%$ if the initial patch fails and a second patch is attempted $(7,28,29)$. Originally developed in 1960 by a general surgeon, Dr. James Gormley, the procedure consists of injecting autologous, unclotted, and sterile blood (typically $10-20$ $\mathrm{mL}$ ) into the epidural space shortly after a diagnosis of PDPH has been determined (30).

\section{Cerebrospinal Fluid Function, Production, and Implications on PDPH}

Cerebrospinal fluid (CSF) is a clear, colorless fluid that inhabits the ventricles and subarachnoid space in the central nervous system. It plays a key role in protecting the brain, ensuring an optimal chemical environment for the proper functioning of neurons, providing brain buoyancy, and helping eliminate metabolic waste products. CSF pressure is regulated via positive and negative feedback of intraventricular pressure at all 3 stages of hydrodynamics: secretion, circulation, and absorption. The average human has about $150 \mathrm{~mL}$ of CSF circulating at any one time. It is primarily produced by the ependymal cells in the choroid plexuses and to a lesser extent, the spinal cord. It then flows from the ventricles to the subarachoid spaces, and then it is filtered by the arachnoid granulations. The CSF is regenerated about 3 - 5 times over each day at a rate of roughly $0.3 \mathrm{~mL}$ per minute (31). Loss of CSF, as occurs during accidental arachnoid disruption, plays a central causal role in the manifestations of the symptoms of PDPH. 


\section{Pathophysiology of PDPH}

While the exact mechanism of PDPH is theoretical, there appears to be a definitive relationship between the loss of CSF and symptom manifestation. Experts have postulated that the loss of CSF impairs buoyancy of the brain, thereby creating caudal intracranial tension on pain-sensitive intracranial structures such as cranial nerves (particularly $\mathrm{V}, \mathrm{IX}$, and $\mathrm{X}$ ), the falx cerebri and tentorium, and blood vessels. In reaction to vessel tension, CSF pressure decreases and cerebral blood vessels dilate. Decreased CSF results in decreased intracranial volume, which results in compensatory cerebral venous dilation. The increased nerve tension and venous dilation are believed to cause the PDPH. When patients with PDPH stand up, intracranial pressure decreases further, resulting in further venous distention and worsening headache (32).

Given the current understanding of PDPH, the incredible success of the epidural blood patch procedure for treating this complication, and the fast pace of CSF turnover and production, it seems logical to postulate that the primary goal in enabling recovery from a PDPH is preventing further CSF leakage from the subarachnoid space.

\section{Proposed Mechanisms for Epidural Blood Patch Efficacy}

Although the exact mechanism by which an epidural blood patch relieves PDPH is not fully understood, 2 main theories have been postulated. The "Plug" theory proposes that blood injected into the epidural space forms a fibrinous clot that adheres to and seals the dural hole, thereby exerting a tamponade effect and preventing further leakage of CSF from the site, and raising the brain back onto its normal fluid cushion. By preventing further CSF leakage and allowing new CSF to fill the subarachnoid space, CSF pressure is restored, providing relief of the PDPH (28). While most headaches are relieved in a timeframe that fits with the rate of CSF regeneration, the "Plug" theory fails to explain how many patients feel immediate relief after the procedure.

The "Pressure Patch" theory suggests that blood or other fluid injected into the epidural space elevates the pressure in the subarachnoid space by compressing the dura instantaneously. CSF in the spinal canal migrates into the cranium and immediately restores the intracranial CSF volume and pressure, thereby alleviating the headache (28). Two studies support this theory as follows. Using pressure transducers in the subarachnoid space during injection of a $15 \mathrm{~mL}$ epidural blood patch on 8 patients, one study found that immediately after a $15 \mathrm{~mL}$ epidural blood patch (delivered at a rate of $2.5 \mathrm{~mL} / 30$ seconds), subarachnoid pressure increased 4-fold, from $20.4 \mathrm{mmH}_{2} \mathrm{O}$ to $81.6 \mathrm{mmH}_{2} \mathrm{O}$ and remained persistently elevated at $68 \mathrm{mmH}_{2} \mathrm{O}$ at 15 minutes post-injection (33). A second study evaluated the progression of blood patches with the use of magnetic resonance imaging technology at 5 separate time points from 30 minutes to 18 hours after blood patch and found that there is a mass effect after administration which appears to resolve within 7 hours of the procedure (34). The increased subarachnoid pressure post-blood patch is likely explained by the mass effect of the epidural blood injectate.

In reality, relief of the PDPH is likely a combination of these 2 proposed theories: initial headache alleviation is accomplished through restoration of intracranial pressure and CSF regeneration contributes to the sustained relief, all the while the reparative processes of the body repair the dural defect (28).

\section{Epidural or Spinal Procedure Timing after a Blood Patch}

Of the many unanswered and debated topics related to PDPH, one that remains unclear is how long after a thecal space disruption associated with either a wet tap or an intrathecal planned anesthetic such as a spinal anesthestic for an elective outpatient procedure can a second procedure be performed? This question is even more unclear if the new procedure includes a steroid medication. As an example, an older patient presenting with a history of lumbar disc disease receives a lumbar epidural steroid injection and an inadvertent wet tap occurs leading to PDPH. Following conservative management and a successful epidural blood patch, it remains unclear as to when would be the best time frame, in terms of patient safety, to consider a second lumbar epidural steroid injection.

\section{Factors Involved in Formulating a Time Frame}

In order to ensure that an epidural injection is safe and effective following placement of an epidural blood patch from a previous dural puncture, it is important to identify the potential risk factors of a subsequent procedure and minimize their risk of occurrence wherever possible. The main risks that these patients face 
include: (1) disruption of the epidural blood patch and ongoing reparative processes, (2) epidural procedure failure, and (3) infection.

\section{Avoiding Disruption of Epidural Blood Patch and Ongoing Reparative Processes}

Understanding the time frame of dural healing in a patient status post epidural blood patch is a critically important factor for the clinician to consider in determining when it is safe for the patient to receive a spinal or epidural procedure. Unfortunately, there are not many studies in the literature that review blood patch progression in humans. One study looked at the evolution of the blood patch in 8 Angora goats that received epidural blood patches after intentional dural punctures. These goats then underwent bilateral lumbar laminectomies at the level of the blood patch at time intervals of one hour, one, 2 , and 4 days, one and 3 weeks, and 3 and 6 months so that the blood patches could be histologically evaluated. The researchers found that at 24 hours, the blood clot still had considerable numbers of intact red and white blood cells with no fibrous reaction. Only after 4 days were immature fibroblasts first noted. Collagen was first seen during the second week and peaked in thickness, to roughly 5 times that of normal dura, at 3 weeks. The thickness of the resulting scar tissue was then noted to shrink back down in size until about 3 months, when the researchers noted that the scar tissue was essentially the same thickness as the underlying dura (29).

Steroid injections may inhibit or prevent proper scar tissue formation and dural healing. It is already well known that exogenous steroids inhibit collagen synthesis (35-37) and tissue healing (38,39). One study looking at the effects of 2 weeks of serial epidural steroid injections on the lumbar dura material properties in canines noted that there were no significant differences in the tensile strength or histologic appearance of the dura as compared to canines given serial epidural injections of saline. However, under electron microscopy, there were decreased numbers of intracytoplasmic mitochondria of dural fibroblasts in steroid injected animals, which may result in impaired healing of the dural defect, although this is only speculative. Unfortunately, given the small time frame of the study, the chronic effects of epidural steroids could not be adequately assessed (40). Nevertheless, this factor must be taken into account for patients who receive multiple epidural steroid injections for chronic pain.

\section{Avoiding Epidural Procedure Failure}

Previous reports have speculated that the fibrous mass of an epidural blood collection may act as a permanent barrier to the spread of injectate and may interfere with subsequent epidural procedures (41). One retrospective case study of 46 parturients noted that patients who had received epidural blood patches for dural puncture were $6 \%$ more likely to experience complications from an epidural anesthetic than patients who had a previous dural puncture but did not receive an epidural blood patch. Furthermore, the study found that patients who experienced previous dural puncture had a $35 \%-40 \%$ chance of experiencing poor epidural analgesia as compared to patients who had no previous dural puncture (42). A recent case report of 2 pregnant women discussed similar findings (43). It may be that epidural blood patches lead to excessive and unremitting scarring that distorts the anatomy of the epidural space, although several studies refute these findings $(9,44)$. One may also consider whether patients in the pain population subgroup have a difference in both complications (PDPH) as well as whether the success of follow-up care is related to a variation in anatomy, especially in those patients who may have spinal pathology.

A retrospective study that evaluated the success of epidural procedures in all patients at a single hospital over a 12 year period found no significant difference in the rate of successful epidural analgesia or anesthesia in surgical patients who had received a blood patch in the past as compared to patients who never had one, $96.6 \%$ versus $94.8 \%$, respectively. Of note, subsequent epidural catheter placement occurred 10 weeks to 7 years after epidural blood patch placement and $96 \%$ of subsequent epidural catheters were placed within one interspace of the patient's prior epidural blood patch. This challenges the theory that an epidural blood patch may produce permanent changes in the epidural space and complicate future epidural injections (9). Additionally, a case report of 3 patients receiving caudal, epidural, or spinal blocks after blood patches placed 105 to 380 days prior all had successful procedures (44).

In addition, there are discrepancies in the literature regarding whether or not scar tissue formation is short lived or long lasting. In actuality, permanent scar tissue formation after epidural blood patch probably occurs in only a small minority of patients given the dearth of case reports on failed epidural procedures in these patients and therefore should not be a significant con- 
cern for this patient population. This conclusion may be incorrect if we consider possible underreporting in the literature.

\section{Avoiding Infection}

A third concern in patients who require epidural or spinal procedures after receiving a blood patch is infection. Given that a subsequent procedure always has a risk of introducing an infection into the epidural space and the fact that blood in the epidural space may serve as a nidus for infection, it is important to know how long free blood and clot remain in the epidural and subarachnoid spaces after a blood patch has been deployed. According to the previously described study, blood cells present in the subarachnoid space hemolyze, are phagocytized, and begin to diffuse into other tissues within the first several days. Xanthochromia, indicative of red cells present in the CSF, is typically absent by the sixth day (29).

Unfortunately, no study in the literature directly addresses when the blood clot in the epidural space completely resolves. Evaluation of the blood patch with MRI shows that the blood spreads about $9-10$ spinal segments when administered to patients in the sitting position (32), and the clot matures at 7 hours and by 18 hours only small, widely distributed clots remain adherent to the thecal sac (34). However, it is unclear when those small clots fully resolve. If it is assumed that blood in the epidural space from an epidural blood patch is resorbed at a similar rate as that from an epidural hematoma, then the process is complete by $4-6$ weeks after the inciting incident $(45,46)$.

While there are several case studies of patients with known bacteremia who received either spinal anesthesia or diagnostic dural puncture and subsequently developed meningitis (47-49), overwhelming evidence that dural puncture during bacteremia causes meningitis is still lacking and the clinical studies that do exist are sparse and conflicting (50). One study found higher rates of subsequent meningitis in patients with known bacteremia when CSF was drawn as compared to patients who did not have a lumbar puncture performed (51). A second study, which was a retrospective chart review of 710 patients admitted to a hospital for removal of potentially infected hip and knee prostheses requiring neuraxial anesthesia found that the subsequent incidence of central nervous system infection was low, despite many patients having ongoing chronic diseases (65\%), using steroids (5.3\%), and having known bacteremia (4.2\%) (52). Given these findings, and the lack of a clear direct causal relationship between bacteremia and subsequent central nervous system infection after a neuraxial procedure, these patients do not appear to be at increased risk of infection.

\section{Conclusions}

In summary, based upon what is known about epidural blood patch healing, the effects of chronic steroid use on the tissue healing capacities of the body, and the time frame of blood resorption from the epidural space, we can better estimate when it is safe enough to perform an epidural procedure on a patient with prior history of epidural blood patch placement.

Assuming that humans follow a similar timetable of scar progression as the goat model studied by DiGiovanni et al 1972 (29), scar tissue achieves maximum thickness within 2 weeks and thins out to normal dural thickness approximately 3 months after epidural blood patch placement in Angora goats. It seems logical, therefore, that it is during this time that the risk of unsuccessful repeat epidural procedures is highest due to a smaller and possibly distorted epidural potential space. Thus, it appears best to only consider performing an epidural procedure for anesthesia or analgesia in patients who clear this time window, the duration of which is unknown in humans. This time frame may also allow for clearance of blood in the epidural space, which otherwise may act as a nidus for infection and also may impair wound healing as may occur when dura is in contact with injected steroids. Further studies are needed to determine how long it takes for the dura to return to normal thickness in humans after epidural blood patch placement and whether needle type or gauge, and the patient's demographics, affects healing time. Ultimately, larger studies are needed to determine when patients are most safe for an epidural after blood patch placement for prior PDPH.

\section{Conflict of Interest}

Each author certifies that he or she, or a member of his or her immediate family, has no commercial association (i.e., consultancies, stock ownership, equity interest, patent/licensing arrangements, etc.) that might pose a conflict of interest in connection with the submitted manuscript.

\section{Author Affiliations}

Dr. Shaparin is Director of Pain Medicine Assistant Professor, Department of Anesthesiology, Assistant 
Professor, Department of Family and Social Medicine, Montefiore Medical Center/Albert Einstein College of Medicine, Bronx, New York.

Dr. Gritsenko is Assistant Professor, Department of Anesthesiology, Assistant Professor, Department of Family and Social Medicine, Montefiore Medical Center/ Albert Einstein College of Medicine Bronx, New York.

Dr. Shapiro is a Resident, Department of Anesthesiology, The Mount Sinai Medical Center / Icahn School of Medicine at Mount Sinai, New York, NY.

Dr. Kosharskyy is Director of Anesthesia for Joint Replacement Center Associate Director Pain Center
Assistant Professor, Department of Anesthesiology, Montefiore Medical Center/Albert Einstein College of Medicine Bronx, New York.

Dr. Kaye, is Chairman, Department of Anesthesiology, Professor, Department of Pharmacology, Director, Interventional Pain Services, Louisiana State University School of Medicine, New Orleans New Orleans, LA.

Dr. Smith was Director of Pain Medicine, Albany Medical Center, Albany, NY; and Professor of Anesthesiology at Albany Medical College, Albany, NY.

\section{References}

1. Brown B, Jones O. Prolonged headache following spinal puncture. Response to surgical treatment. J. Neurosurg 1960; 19:349-350.

2. Cass W, Edelist G. Postspinal headache. Successful use of epidural blood patch 11 weeks after onset. JAMA 1974; 227:786-787.

3. Clivatti J, Siddiqui N, Goel A, Shaw M, Crisan I, Carvalho JC. Quality of labour neuraxial analgesia and maternal satisfaction at a tertiary care teaching hospital: A prospective observational study. Can J Anaesth 2013; 60:787-795.

4. Pan PH, Bogard TD, Owen MD. Incidence and characteristics of failures in obstetric neuraxial analgesia and anesthesia: A retrospective analysis of 19,259 deliveries. Int J Obstet Anesth 2004; 13:227-233.

5. Reynolds F. Dural puncture and headache. BMJ 1993; 306:874-876.

6. Stendell L, Fomsgaard JS, Olsen KS. There is room for improvement in the prevention and treatment of headache after lumbar puncture. Dan Med J 2012; 59:A4483.

7. Abouleish E, Vega S, Blendinger I, Tio TO. Long-term follow-up of epidural blood patch. Anesth Analg 1975; 54:459-463

8. Liu S, Carpenter RL, Neal JM. Epidural anesthesia and analgesia. Their role in postoperative outcome. Anesthesiology 1995; 82:1474-1506.

9. Hebl JR, Horlocker TT, Chantigian RC, Schroeder DR. Epidural anesthesia and analgesia are not impaired after dural puncture with or without epidural blood patch. Anesth Analg 1999; 89:390-394.
10. Turnbull DK, Shepherd DB. Post-dural puncture headache: pathogenesis, prevention and treatment. $\mathrm{Br} \mathrm{J}$ Anaesth 2003; 91:718-729.

11. Lambert DH, Hurley RJ, Hertwig L, Datta $S$. Role of needle gauge and tip configuration in the production of lumbar puncture headache. Reg Anesth 1997; 22:66-72.

12. Bezov D, Ashina S, Lipton R. Post-dural puncture headache: Part II--prevention, management, and prognosis. Headache 2010; 50:1482-1498.

13. Ghaleb A. Postdural puncture headache. Anesthesiol Res Pract 2010. EPub. August 11 2010. Pgs 1-6

14. Lynch J, Arhelger S, Krings-Ernst I. Postdural puncture headache in young orthopaedic in-patients: comparison of a $0.33 \mathrm{~mm}$ (29-gauge) Quincke-type with a $0.7 \mathrm{~mm}$ (22-gauge) Whitacre spinal needle in 200 patients. Acta Anaesthesiol Scand 1992; 36:58-61.

15. van Oosterhout WP, van der Plas $A A$, van Zwet EW, Zielman R, Ferrari MD, Terwindt GM. Postdural puncture headache in migraineurs and nonheadache subjects: A prospective study. Neurology 2013; 80:941-948.

16. Wadud R, Laiq N, Qureshi FA, Jan AS. The frequency of postdural puncture headache in different age groups. J Coll Physicians Surg Pak 2006; 16:389-392.

17. Vilming ST, Schrader H, Monstad I. The significance of age, sex, and cerebrospinal fluid pressure in post-lumbarpuncture headache. Cephalalgia 1989; 9:99-106.

18. Amorim JA, Gomes de Barros MV, Valenca MM. Post-dural (post-lumbar) puncture headache: risk factors and clinical features. Cephalalgia 2012; 32:916-923.

19. de Almeida SM, Shumaker SD, LeBlanc SK, Delaney P, Marquie-Beck J, Ueland S, Alexander T, Ellis RJ. Incidence of post-dural puncture headache in research volunteers. Headache 2011; 51:1503-1510.

20. Bezov D, Lipton RB, Ashina S. Post-dural puncture headache: Part I diagnosis, epidemiology, etiology, and pathophysiology. Headache 2010; 50:1144-1152.

21. Strupp M, Schueler O, Straube A, Von Stuckrad-Barre S, Brandt T. "Atraumatic" Sprotte needle reduces the incidence of post-lumbar puncture headaches. Neurology 2001; 57:2310-2312.

22. Thomas SR, Jamieson DR, Muir KW. Randomised controlled trial of atraumatic versus standard needles for diagnostic lumbar puncture. BMJ 2000; 321:986-990.

23. Santanen $U$, Rautoma $P$, Luurila $H$, Erkola O, Pere P. Comparison of 27-gauge (0.41-mm) Whitacre and Quincke spinal needles with respect to post-dural puncture headache and nondural puncture headache. Acta Anaesthesiol Scand 2004; 48:474-479.

24. Ahmed SV, Jayawarna C, Jude E. Post lumbar puncture headache: Diagnosis and management. Postgrad Med J 2006; 82:713-716.

25. Waise S, Gannon D. Reducing the incidence of post-dural puncture headache. Clin Med 2013; 13:32-34.

26. Reina MA, de Leon-Casasola OA, Lopez A, De Andres J, Martin S, Mora M. An in vitro study of dural lesions produced by 25-gauge Quincke and Whitacre needles evaluated by scanning electron 
microscopy. Reg Anesth Pain Med 2000; 25:393-402.

27. Ghaleb A, Khorasani A, Mangar D. Postdural puncture headache. Int ] Gen Med 2012; 5:45-51.

28. Duffy PJ, Crosby ET. The epidural blood patch. Resolving the controversies. Can ] Anaesth 1999; 46:878-886.

29. DiGiovanni AJ, Galbert MW, Wahle WM. Epidural injection of autologous blood for postlumbar-puncture headache. II. Additional clinical experiences and laboratory investigation. Anesth Analg 1972; 51:226-232.

30. Gormley J. Treatment of post spinal headache. Anesthesiology 1960; 21:565-566.

31. Wang PW, Avellino, AM. Hydrocephalus in Children. In: Rengachary SS, Ellenbogen RG (eds). Principles of Neurosurgery. 2nd Edition. Elsevier Mosby, 2005. New York

32. Candido KD, Stevens RA. Post-dural puncture headache: Pathophysiology, prevention and treatment. Best Pract Res Clin Anaesthesiol 2003; 17:451-469.

33. Coombs DW HD. Subarachnoid pressure with epidural blood patch. Regiona Anesthesia and Pain Medicine 1979; 4:3-6.

34. Beards SC, Jackson A, Griffiths AG, Horsman EL. Magnetic resonance imaging of extradural blood patches: Appearances from $30 \mathrm{~min}$ to $18 \mathrm{~h}$. $\mathrm{Br} \mathrm{J} \mathrm{An}$ aesth 1993; 71:182-188.

35. Nakagawa H, Fukuhara M, Tsurufuji S. Effect of a single injection of betamethasone disodium phosphate on the synthesis of collagen and noncollagen pro- tein of carrageenin granuloma in rats. Biochem Pharmacol 1971; 20:2253-2261.

36. Behrens F, Shepard N, Mitchell N Metabolic recovery of articular cartilage after intra-articular injections of glucocorticoid. J Bone Joint Surg Am 1976; 58:1157-116o.

37. Oikarinen Al, Vuorio El, Zaragoza EJ, Palotie A, Chu ML, Uitto J. Modulation of collagen metabolism by glucocorticoids. Receptor-mediated effects of dexamethasone on collagen biosynthesis in chick embryo fibroblasts and chondrocytes. Biochem Pharmacol 1988; 37:1451-1462.

38. Green JP. Steroid therapy and wound healing in surgical patients. $\mathrm{Br} J$ Surg 1965; 52:523-525

39. Wiggins ME, Fadale PD, Barrach $\mathrm{H}$, Ehrlich MG, Walsh WR. Healing characteristics of a type I collagenous structure treated with corticosteroids. Am J Sports Med 1994; 22:279-288.

40. Slucky AV, Sacks MS, Pallares VS, Malinin TI, Eismont FJ. Effects of epidural steroids on lumbar dura material properties. J Spinal Disord 1999; 12:331-340.

41. Rainbird A, Pfitzner J. Restricted spread of analgesia following epidural blood patch. Case report with a review of possible complications. Anaesthesia 1983; 38:481-484.

42. Ong BY, Graham CR, Ringaert KR, Cohen MM, Palahniuk RJ. Impaired epidural analgesia after dural puncture with and without subsequent blood patch. Anesth Analg 1990; 70:76-79.

43. Collier CB. Blood patches may cause scarring in the epidural space: Two case reports. Int J Obstet Anesth 2011; 20:347-351.

44. Abouleish E, Wadhwa RK, de la Vega S, Tan RN, Jr., Lim Uy N. Regional analgesia following epidural blood patch. Anesth Analg 1975; 54:634-636.

45. Bullock R, Teasdale G. ABC of major trauma. Head injuries - I. BMJ 1990; 300:1515-1518.

46. Bullock R, Teasdale G. ABC of major trauma. Head injuries - II. BMJ 1990; 300:1576-1579.

47. Myers MG, Wright PF, Smith AL, Smith $\mathrm{DH}$. Complications of occult pneumococcal bacteremia in children. J Pediatr 1974; 84:656-66o.

48. Fischer GW, Brenz RW, Alden ER, Beckwith JB. Lumbar punctures and meningitis. Am J Dis Child 1975; 129:590-592.

49. Berman RS, Eisele $\mathrm{JH}$. Bacteremia, spinal anesthesia, and development of meningitis. Anesthesiology 1978; 48:376-377.

50. Chestnut DH. Spinal anesthesia in the febrile patient. Anesthesiology 1992; 76:667-669.

51. Teele DW, Dashefsky B, Rakusan T, Klein JO. Meningitis after lumbar puncture in children with bacteremia. N Engl J Med 1981; 305:1079-1081.

52. Gritsenko K, Marcello D, Liguori GA, Jules-Elysee K, Memtsoudis SG. Meningitis or epidural abscesses after neuraxial block for removal of infected hip or knee prostheses. $\mathrm{Br}$ J Anaesth 2012; 108:485-49o. 
